\title{
The Effectiveness of Self-Knowledge Training on Self-Esteem and Peer Relations in Junior High School Female Students in Farashband, Iran
}

Farzad Poorgholami

Department of Educational Sciences and Psychology, Payame Noor University (PNU) P.O. Box: 19395-3697, Tehran, IR of Iran

Ensieh Aghaee

Department of Educational Sciences and Psychology, Payame Noor University (PNU) P.O. Box: 19395-3697, Tehran, IR of Iran

Elham Farsimadan

Department of Educational Sciences and Psychology, Payame Noor University (PNU) P.O. Box: 19395-3697, Tehran, IR of Iran

\section{Ali Mohammad Ahmadi Gharacheh*}

PhD Student in Planning Distance Education, Department of Educational Sciences and Psychology, Payame Noor University (PNU), P.O. Box: 19395-3697, Tehran, IR of IRAN. *Corresponding Author. Amag2004@gmail.com

\author{
Doi:10.5901/mjss.2015.v6n6s6p121
}

Abstract

The primary objective of the current study was to investigate the effect of self-esteem and peers relations in junior high school female students in Farashband, Iran. The statistical population of the study was all junior high school female students in Farashband, Iran in 2012-2013. The study sample consisted of 30 students using multi-Step random sampling method from the intended population and divided into two experimental and control groups (15 subjects in each group). The study was conducted as a quasi-experimental research. The instruments applied in this study included Rosenberg's Self-esteem Scale (RSES) Questionnaire and Index of Peer Relations (IPR) of Hudson (1992). After the random selection of experimental and control groups, a pre-test was performed on both groups. Then, the experimental intervention (self-knowledge training) was conducted in 8 sessions of 1.5 hours and after the completion of the training programs; the post-test was done on both groups. The analysis of the results of Independent sample T-test on the difference between the mean scores of pre-test and post-test showed that the self-knowledge training has resulted in a significant effect on the enhancement of self-esteem scores $(P<0.002)$ and an increase in peer relations scores $(P<0.001)$.

Keywords: Self-knowledge, Self-esteem, Peer Relations.

\section{Introduction}

Adolescence is a critical period that is a golden opportunity to actualize God's blessings through achieving several and diverse experiences and intrinsic facilities. Also, there exist a lot of difficulties in this age. In this period, adjustment becomes confused, symptoms of physical and mental maturity manifests one after another, and a kind of surprise and anxiety can be observed in the individual (Ghaimi, 2001). Due to some specific problems, this period is associated with a kind of confusion and loss of confidence which decline daily normal activities of adolescents. By identifying factors affecting mental, emotional and physical health of adolescents, they can be assisted in order to experience a good life. So, considering advantages and enhancing confidence, self-esteem, and self-compassion are the most important things that scientists and scholars of education have had special attention to. The thing that adolescents really need is personality reverence. Encouraging adolescents, acquainting them with successful behavioral patterns, strengthening their social skills, avoiding humiliating behaviors, and ultimately, teaching correct ways to overcome the adversities of life are the most important steps to be taken to help adolescents (Afrouz, 1992). Self- esteem is one of the most important factors for the desired development of personality in children and adolescents. Having strong will, decision-making power, 
initiative, creativity, and thought and mental health are directly related to self-esteem. Self-esteem is the condition in which a person considers himself as a good person and successfully faces with the initial challenges of life and it has the worth of being happy. From the perspective of Cooper Smith, self-esteem is the individual's evaluation on his own or judgments about his value. There is an interrelation between self-esteem and individual's view on his ability so that by reduction of self-esteem, the sense of weakness and disability is created in person, vice versa; by increasing it, the sense of empowerment and volubility is revived in person (Brandon, 1998). Self-esteem is considered as one of the determinants of human behavior. In fact, perception and judgment that people have determine how they deal with different issues. A person who has low self-esteem and self-worth and no respect, may be isolated, withdrawn or aggressive or shows antisocial behavior (see Mackie and Smith, 2002). Coopersmith (1981) believes that self-esteem means the self-assessment of the individual. It is acquired through attention to him, and is a sign of attitude to approval or disapproval, and the extent to which he believes in his own ability, achievement and self-worth.

Adolescent period is considered as a prominent stage of social and psychological development and growth in person.

In this course, need to emotional balance, perception of existential value of self, achievement of necessary social skills to make friends, knowledge of healthy and effective living and how to enjoy it are the most important needs of adolescents. So, to help the adolescents seems necessary for the development and growth of social skills required for effective and productive life in the community. Also, due to the occurrence of specific issues, this period can be associated with a kind of confusion along with the reduction of self-esteem, inferiority complex, and negative self-concept and feeling of anger and aggression which reduces the normal activities and social interactions. By identifying the factors affecting mental, emotional, and physical health of adolescents, they can be helped to continue a good life. Considering advantages and enhancing confidence, self-esteem, and self-compassion are the most important things that should be specially taken into account. Reverence of personality is something that adolescents severely require. One of the important reasons for the interest of researchers in the concept of self-esteem is its potential impact on health so that French and Vargo named self-esteem as a cultural buffer against anxiety (Afrouz, 1992). In adolescence, camaraderie and friendship with peers, group cohesion, and admission with friends are very important for adolescents. If adolescents have the lack of desired social status commensurate with what they think among classmates, their main function i.e. the acquisition of knowledge and academic achievement will be disrupted. However, because the person finds that he is not interested and attended by others, he will tend to isolation and greatly reduce the amount of his social connections. Withdrawal and escape from others put gradually negative images on self and feeling of incompetence and inefficiency associated with decrease in self-esteem are developed in the person and therefore, he considers himself unable to cope with problems and solve them (Najjaria, and Ibrahimi, 1990). Johnson (2000) and Wentzel and Caldwell (1997) showed that there is a significant positive relationship between mutual friendships and peer-acceptance with academic achievement of male and female students in secondary school (cited by Yarmohammadian, 2002). In 1992, Switzer conducted a study on the relationship between self-concept and psychological adjustment of adolescents. The results showed that adolescents with disorder in adjustment had lower self-concept scores (Taghizadeh, 2000). Gran et al (1992) examined the relationship among friendships, peer-acceptance and self-esteem in 542 adolescents. Results indicated that subjects who had mutual relations with their peers achieved higher scores in self-esteem scale compared to those who had no such friendships (cited by Yarmohammadian, 2002). The role of peers is crucial in the life of children or adolescents. Positive relationship with peers depends on social competence, success in school, and public compromise; however, poor social competence and rejection by peers lead to the next non- compromises and psychological and social - inefficiencies in adulthood (Robm, Bakowski, and Parker, 1997). Individuals with high self-knowledge were described by their friends as: they have more insight to themselves in interaction with others, are more aware of their inner psychological experiences, and have greater control over themselves.

Although fundamental questions have so far been asked about the nature of human mind and its ability for selfknowledge, the concept of self-knowledge has not gained its principal status in psychology as a major issue. The importance of self-knowledge in various fields of research including psychodynamic tradition, personality researches in which the personality traits are assessed through self-rating questionnaires and social psychological researches on the nature of self-concept is noteworthy (Ghorbani et al, 2003). Kilhstrom and Klin (1997) examined the concept from a cognitive perspective. They postulate that "Self' is the mental representation of the own; in other words, "Self' expresses our knowledge of own. The founder of "Self Psychology", Heinz Kohut has addressed the Steps of growth and development of "self" from a psychoanalytic perspective. For him, "self" is a total unit with coherence in space and continuity in time and the axis of human action and receiver of his effects. "Self" is the source of experiences and relationships of an individual and the factor of psychological and behavioral functions. Thus, "self", in its broadest sense, refers to the totality of an individual in contrast with surrounding objects. Based on the conceptualization by Ghorbani et al 
(2003), self-knowledge is the continual awareness about psychological states and the ability to distinguish and analyze the content of current experiences and the active cognitive processing on "self" and referring to the past events whose conclusion is the creation of a larger vision to guide behavior and the formation of more complex and complete individual schema. According to what was mentioned, "Self-knowledge" is a type of dynamic, adapted and integrative psychological process which has a temporal nature. Investigating self-concept, especially for adolescence is due to its transient nature. According to Ericsson, the emergence of a more fully developed self-concept is one of the main tasks related to growth in this phase of life cycle (Beaty, 1992). Research shows that in this period, basic definitions of "self" become obsolete in face with rapid social and physical changes and should again be designed in accordance with perceived characteristics of important authorities, especially parents and peers. The reported temporary loss of positive self-esteem and changes in the perception of "self" may indicate that this redevelopment process has been started (Seiffge-Krenke, 1990). In cognitive perspective, self-concept is considered as a set of cognitive structures about "self" that are used to recognize and interpret stimulus related to "self" in the social experiences of an individual. From this view, self-concept works as any other cognitive construction. Self-concept has an impact on the type of stimulus attended, as well as the memory, prediction, deduction, and behavior. Self-concept operates as a selective mechanism in information processing (Lot et al., 1996; Ybrandt 2008). Thus, the findings of altimetry reports reflect the role of self- knowledge in explaining behaviors and interpersonal relations (Ghorbani et al, 2003). According to what was said, as a fundamental structure in anticipating personality-related processes, the necessity to attend self- knowledge is felt more than ever. Therefore, this study aims to investigate the effect of self- knowledge training on self-esteem and peer relations in students.

\section{The Study Hypotheses}

$\mathrm{H}_{1}$ : Self-knowledge training enhances the self-esteem of students.

$\mathrm{H}_{2}$ : Self-knowledge training improves peer relations in students.

\section{Methodology}

The study was a quasi-experimental research. The statistical population of the study was all junior high school female students in Farashband in 2012-2013 that were 180 subjects according to the report of the Department of Education. The study sample consisted of 30 students who were selected using multi-step random sampling method among from the desired population and divided into two experimental and control groups (15 subjects in each group). The instrument used in this study was Rosenberg's Self-esteem Scale (RSES) Questionnaire and Index of Peer Relations (IPR) of Hudson (1992). After the random selection of experimental and control groups, a pre-test was performed on both groups. Then, the experimental intervention (self-knowledge training) was presented in 8 sessions of 1.5 hours and after the completion of the training program; a post-test was conducted on both groups.

\section{Instrument}

Rosenberg's Self-esteem Scale (RSES) Questionnaire: This scale was prepared and introduced to measure overall self-esteem by Morris Rosenberg and composed of 10 articles (Rosenberg, 1965). Subjects are asked to carefully read ten words and give positive response to the statements that are true about them and negative response to the statements that are not true about them. Agreed response to the items of 1 to 5 receives +1 . The opposed response to the items of 1 to 5 receives -1 , while the agreed response to the items of 1 to 6 receives +10 . Score above zero indicates higher selfesteem and score less than zero indicates low self-esteem. Score +10 shows very high self-esteem, while -10 reveals very low self-esteem. The higher the score, the higher the level of self-esteem is and vice versa. Several studies have been conducted to evaluate the reliability and validity of Rosenberg's Self-esteem Scale. Lorenzo (1998) reported the Cronbach's alpha of $78 \%$ for the English version and $77 \%$ for Spanish version. In this study, the validity of the questionnaire was calculated using Cronbach's alpha that the calculated coefficient $(X=73 \%)$ indicates the high validity of the questionnaire.

Index of Peer Relations (IPR) of Hudson Questionnaire: is a 25-item instrument designed in order to measure the extent, severity, and magnitude of the problem which the subject has with peer group. This instrument can be used as an overall measure of communication problems with peers. This scale has two cut-off points. The first cut-off point is the score of $30( \pm 5)$ whose lower scores indicate the absence of a significant clinical problem in this area, while scores above 30 indicate a significant clinical problem. Second cut-off point is 70 reflecting the experience of extreme stress and possibility of handling some types of violence to deal with a variety of problems. Using sample consisted of 170 
subjects who were selected for consultation; norms of the instrument were implemented so that among from them, 50 cases were evaluated as people who had no problem with their peers by their therapists. For these groups, the means were 55.9 and 20.8, respectively in IPR. This scale has the alpha of 0.94 which indicates excellent mental stability and excellent (low) standard error of 0.44 . Data of test-retest reliability are not available. This scale has excellent reliability by comparison with the known groups so that it can show statistically significant difference between the subjects who have communication problems with their peers according to their statement and subjects' statement and those who have no communication problems with their peers.

\section{Results}

Hypothesis 1: Training self-knowledge skills has an effect on increasing the self-esteem of students.

Table 1: T- Statistics for comparing the mean scores of self-esteem of students in the experimental and control groups

\begin{tabular}{|c|c|c|c|c|c|c|c|c|c|}
\hline \multirow{2}{*}{ Variable } & \multicolumn{3}{|c|}{ Experimental } & \multicolumn{3}{|c|}{ Control } & \multirow{2}{*}{ T-Statistics } & \multirow{2}{*}{ Degree of freedom } & \multirow{2}{*}{ Significance } \\
\hline & Number & Mean & SD & Number & Mean & SD & & & \\
\hline elf-esteem & 15 & 10.82 & 8.65 & 15 & 4.24 & 3.90 & 2.23 & 27 & 0.002 \\
\hline
\end{tabular}

In the two experimental and control groups, the comparison of the self-esteem of students was obtained based on the calculations through t-test and the level of significance was equal to 0.002 and less than $\alpha=0.05$ in the experimental and control groups. Consequently, it can be said that self-esteem of students in the experimental and control groups has a significant difference and comparison of the means in the two groups shows that self-esteem of students in the experimental group has been better than that in the control group. In other words, self- knowledge training has resulted in an increase in the self-esteem of students.

\section{Training Self - Knowledge Skills Influences the Improvement of Relationships with Peer Students}

Table 2: T-test statistics to compare the mean scores of the students' relationships with peers in the experimental and control groups

\begin{tabular}{|c|c|c|c|c|c|c|c|c|}
\hline \multirow{2}{*}{ Variable } & \multicolumn{3}{|c|}{ Experimental } & \multicolumn{2}{|c|}{ Control } & \multirow{2}{*}{ T-Statistics } & \multirow{2}{*}{ Degree of freedom } & \multirow{2}{*}{ Significance } \\
\hline & Number & Mean & SD & Number & \begin{tabular}{|l|l|} 
Mean & SD \\
\end{tabular} & & & \\
\hline Peer relations & 15 & 11.21 & 9.26 & 15 & \begin{tabular}{|l|l|}
1.21 & 4.70 \\
\end{tabular} & 4.81 & 27 & 0.001 \\
\hline
\end{tabular}

Comparison of peer relationships in students in the experimental and control groups was obtained based on calculations of t-test. Given the level of significance obtained as less than $a=0.05$, it can be said that relationships with peers have $a$ significant difference in the experimental and control groups and the comparison of means indicates that students in the experimental group have better relationships with their peers than students in the control group. In other words, selfknowledge training has been effective on improving students' relationships with their peers.

\section{Discussion and Conclusion}

Human always tries to achieve skills for facilitating their relation with others and add expand their own personal developments. Self-knowledge is one of these skills that play a widespread role in interpersonal relationships and strengthens behaviors such as independence, self-confidence, and self- awareness in the person (Kilkus, 1990). Selfesteem is one of the basic human needs in all scientific and moral classes and degrees (Koshan and Vaghei, 2007). One of the problems that has a deterrent effect on the effectiveness of adolescents and avoid the healthy formation of identity and efflorescence of their talents and intellectual and emotional forces is the disability in establishing and maintaining social relationships. Self-knowledge and awareness of one's special talents and skills can be effective in the creation of health relationships with others. Considering properties and positive aspects of behaviors of adolescents rather than considering and focusing on their weaknesses and awareness of their moral and behavioral properties are important. So, it is necessary for young people to better recognize themselves and their attitude towards the compliance with reality. The self-awareness of personality can help them find a right path in their life. When teenagers have better relationships with their peers and can provide a positive assessment about themselves, others and life, they feel more volubility and in 
order to achieve this view, they should be aware of their positive properties, abilities, beauties and special talents, respect them and be pleased to have these properties. The current study aimed to examine the effect of self-knowledge training on self-esteem and peer relations in Junior high school students. The findings are summarized as follows:

The first hypothesis: Self-knowledge skill training is effective in increasing self-esteem in students.

The above hypothesis was tested using t-test for independent groups. After comparing the mean of the self-esteem of students in both experimental and control groups, the level of significance of this variable was equal to 0.002 in both groups and less than $a=0.05$. Consequently, it can be said that self-knowledge training could significantly increase selfesteem in the experimental group. To compare the obtained results, there is no similar study which exactly shows the effect of self-knowledge training on increasing self-esteem.

The second hypothesis: Self-knowledge skill training is effective in improving peer relations in students.

Comparison of the peer relationships in students in the experimental and control groups was obtained based on the calculations of t-test. Given the obtained level of significance which is less than $a=0.05$, it can be said that the relationships with peers have a significant difference in the experimental and control groups and comparison of the means indicates that students in the experimental group have better relationships with their peers than students in the control group. In other words, self-knowledge training has been effective on improving students' relationships with their peers.

\section{References}

Afrouz, G.H. (1992), Issues in Psychology and Education of Children and Adolescents, PTO Publication Taghizade, M.A. (2000), Gentle Quiet Adolescence (with an Emphasis on Education and Self-Perception) Ghaemi, A., (2001), Development and Education of Girls, Tehran: Publication of Parent-Teacher Interview Lot, Brnais et al, (1996), Foundations of Social Psychology, translated by Tahorian J. and Maneshi Tosi M. T., Volume II, Mashhad: Cultural Department of Astan Quds Razavi

Najarian, B. and Abraham A. (1990), the Role of Social Support in Individual Adjustment, Journal of Scientific Information, Vol. 6, No. 8, Pp.: 4-6

Yarmohammadian, M.H. (2002), the Investigation of the Relationship between Mutual Friendships, Peer-Acceptance, Self-Concept, and Social Adjustment with Academic Achievement among Junior high school female students in Isfahan, Journal of Education and Psychology, Ferdowsi University; pp. 6-8

Yarmohammadian, M.H. (2002). Investigation of relations among mutual friendships, peer acceptance, self-concept, and social adjustment with the academic achievement of female students in the third year of school, Studies in Psychology and Education, Ferdowsi University. Pp: 6-8

Beaty, L.A., (1992), Adolescent self-perception as a function of vision loss Adolescence, 27(107), 707-714

Branden N. A., (1998), Woman's Self-Esteem: Struggles and triumphs in the search for identity, London UK: Amazon.

Cooper S. S. (1981). The antecedents of self- esteem, 2nd Ed., Pala Alto, CA: Counseling Psychologists

Ghorbani, N. Bing 'M. N. Watson. P. J. Davison. H. K. \& Lebreton. D. L. (2003). Individualist and collectivist values: evidence of Adjustment in Iran and United States. Personality and Individual Difference, 35 ، 433-447

Hudson ‘W.W. (1992). The WALMYR Assessment Scales Scoring Manual, Tempe ،ZA: WALMYR publishing co

Rosenberg. M. (1965), Social and the adolescent self-Images, Princeton, N.J., Princeton University Press

Rubm, K. H., Bukowski, W., \& Parker, J. G. (1997), Peer interactions, relationships, and groups, In N

Eisenberg (Ed,), W, Damon (Series Ed,), Handbook of Medical psychology (Vol. 3), Social, emotional and personality development (5 ed., pp.619-700), New York: Wiley.

Kilhstrom, J.F. \& Klin S.B., (1997), Self-knowledge and self-awareness, In J. G. Snodgrass \& R. L. Thumpson (Edg.), the self across Psychology: Self-recognition ‘Self-awareness ،and Self- concept, Annals of the New York Academy of Sciences‘818 ‘5-17

Killkus, S. P. (1990). Self-assertiveness and nursing: A different voice profession. Nursing Outlook, 38: 143-145

Kooshan, M., \& Vagheie, S., (2007), Psycho-nursing of mental health, Tehran: Andisheh Rafie Pub.

Macke ‘M.D. \& Smith ‘R.E. (2002), Social psychology, (2nd, ed.) U.S.A: Psychology press. 285

Seiffge- Krenke, I., (1990). Developmental processes in self-concept and coping behavior, In H. Bosma \& S. Jackson (Eds), Coping and Self-Concept in Adolescence, Berlin Heidelberg: Springer-Verlag, 49-68. 